\title{
Upregulation of the Sarco-Endoplasmic Reticulum Calcium ATPase 1 Truncated Isoform Plays a Pathogenic Role in Alzheimer's Disease
}

\author{
Renaud Bussiere ${ }^{1,2}{ }^{\mathbb{D}}$, Bénédicte Oulès ${ }^{3}$, Arnaud Mary ${ }^{1}$, Loan Vaillant-Beuchot ${ }^{1}$, \\ Cécile Martin ${ }^{1}$, Wejdane El Manaa ${ }^{1}$, Déborah Vallée ${ }^{1,4}{ }^{\mathbb{D}}$, Eric Duplan ${ }^{1}$, \\ Patrizia Paterlini-Bréchot ${ }^{5}$, Cristine Alves Da Costa ${ }^{1}$, Frédéric Checler ${ }^{1}$ and Mounia Chami ${ }^{1, *}$ D \\ 1 Université Côte d'Azur, INSERM, CNRS, IPMC, France, Laboratory of excellence DistALZ, 660 route des \\ Lucioles, 06560 Sophia-Antipolis, Valbonne, France; r.bussiere@imperial.ac.uk (R.B.); \\ mary@ipmc.cnrs.fr (A.M.); vaillant@ipmc.cnrs.fr (L.V.-B.); ccilmart1@gmail.com (C.M.); \\ elmanaa@ipmc.cnrs.fr (W.E.M.); deborah-vallee@hotmail.fr (D.V.); duplan@ipmc.cnrs.fr (E.D.); \\ acosta@ipmc.cnrs.fr (C.A.D.S.); checler@ipmc.cnrs.fr (F.C.) \\ 2 Present address: UK Dementia Research Institute, Imperial College London, Department of Medicine, \\ Burlington Danes Building, Hammersmith Hospital Campus, Du Cane Road, London W12 0NN, UK \\ 3 Institut Cochin, Team Cutaneous Biology, INSERM U1016, CNRS UMR8104, Université Paris Descartes, \\ 24 rue du Faubourg Saint-Jacques, 75014 Paris, France; benedicte.oules@yahoo.fr \\ 4 Université Côte d'Azur, INSERM, U1065, C3M, 06200 Nice, France \\ 5 Unité INSERM U1151 (Eq. 13), Faculté de Médecine Paris Descartes, 75993 Paris CEDEX 14, France; \\ patriziapaterlini@gmail.com \\ * Correspondence: mchami@ipmc.cnrs.fr; Tel.: +33-493-953-457; Fax: +33-493-953-408
}

Received: 12 November 2019; Accepted: 26 November 2019; Published: 28 November 2019

\begin{abstract}
Dysregulation of the Endoplasmic Reticulum (ER) $\mathrm{Ca}^{2+}$ homeostasis and subsequent ER stress activation occur in Alzheimer Disease (AD). We studied the contribution of the human truncated isoform of the sarco-endoplasmic reticulum $\mathrm{Ca}^{2+}$ ATPase 1 (S1T) to AD. We examined S1T expression in human AD-affected brains and its functional consequences in cellular and transgenic mice $\mathrm{AD}$ models. S1T expression is increased in sporadic AD brains and correlates with amyloid $\beta(A \beta)$ and ER stress chaperone protein levels. Increased S1T expression was also observed in human neuroblastoma cells expressing Swedish-mutated $\beta$-amyloid precursor protein ( $\beta \mathrm{APP}$ ) or treated with $\mathrm{A} \beta$ oligomers. Lentiviral overexpression of S1T enhances in return the production of APP C-terminal fragments and $A \beta$ through specific increases of $\beta$-secretase expression and activity, and triggers neuroinflammation. We describe a molecular interplay between S1T-dependent $\mathrm{ER} \mathrm{Ca}^{2+}$ leak, ER stress and $\beta$ APP-derived fragments that could contribute to $\mathrm{AD}$ setting and/or progression.
\end{abstract}

Keywords: Alzheimer disease; amyloid $\beta$; amyloid precursor protein; BACE1; C83; C99; endoplasmic reticulum stress; neuroinflammation; truncated isoform of the sarco-endoplasmic reticulum $\mathrm{Ca}^{2+}$ ATPase 1 (S1T)

\section{Introduction}

Alzheimer disease (AD) is a common age-dependent neurodegenerative disease that accounts for most of reported senile dementia cases [1]. The pathological features of AD include the formation of intracellular neurofibrillary tangles (NFTs) composed of hyperphosphorylated Tau, and the extracellular deposition of amyloid- $\beta(A \beta)$ aggregates derived from the sequential processing of the $\beta$ amyloid precursor protein ( $\beta$ APP) by $\beta$ - and $\gamma$-secretases [2]. At the cellular level, perturbations of the endoplasmic reticulum $(E R)$ calcium $\left(\mathrm{Ca}^{2+}\right)$ signalling have emerged as key features 
in AD-affected brains and models [3-5]. AD is also one of the prototypical proteinopathies characterized by cortical and hippocampal protein accumulation and aggregation, synaptic impairments, neuronal loss and consistent neuroinflammation [5-7].

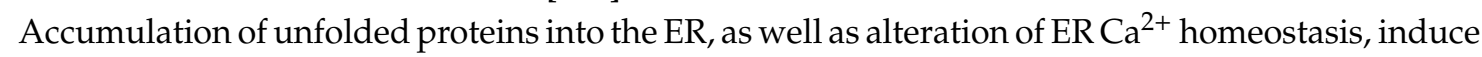
ER stress eliciting unfolded protein response (UPR) $[8,9]$. Chronic ER stress implicates the mitochondrial apoptotic pathway. $\mathrm{Ca}^{2+}$ fluxes from ER to mitochondria, tuned by physical interaction between the two organelles, emerged as a key regulator of this pathway [10-12]. In this context, we reported that the human truncated isoform of the Sarco-endoplasmic reticulum $\mathrm{Ca}^{2+}$ ATPase 1 (S1T) [13] triggers and amplifies ER stress response, leading to subsequent cell commitment to apoptosis through the control of $\mathrm{Ca}^{2+}$ mobilization from ER to mitochondria [14].

We report herein the increase of the human S1T protein expression in a cohort of human sporadic AD-derived post-mortem brains as well as in a cellular AD model. S1T elevation is mimicked by oligomeric $A \beta$ treatment and in return enhances $\beta$ APP processing and the production of $\beta$ APP-derived toxic fragments (i.e., $C 99$ and $A \beta$ ) in in vitro and in vivo AD models. Mechanistically, we find that S1T-mediated elevation of APP processing occurs through the up-regulation of BACE1 expression and enhanced activity, but not $\gamma$-secretase complex expression and activity. Interestingly, we also document that $\mathrm{S} 1 \mathrm{~T}$ expression induces a neuroinflammatory response in vitro and in vivo.

\section{Material and Methods}

\subsection{Human Brain Samples}

All procedures performed in studies involving human participants were in accordance with the ethical standards of the institutional and/or national research committee and with the 1964 Helsinki declaration and its later amendments or comparable ethical studies. Informed consent for tissue donation for research is obtained by the Brain Bank NeuroCEB and has been declared at the Ministry of Higher Education and Research (agreement AC-2013-1887) under their approval procedures.

Brain samples were obtained from the Brain Bank "NeuroCEB" run by a consortium of Patients Associations: ARSEP (association for research on multiple sclerosis), CSC (cerebellar ataxias), and France Parkinson. The consents were signed by the patients themselves or their next of kin in their name, in accordance with the French Bioethical Laws. Cases were anonymized, but information was provided regarding sex, age at death, and neuropathology (Table 1).

Table 1. Demographic data and neuropathological findings related to human brain samples used in SDS-PAGE analyses (temporal lobe), and brain-derived slices used in immunohistochemistry analyses (T1 region of the temporal lobe).

\begin{tabular}{ccccc}
\hline & $\begin{array}{c}\text { Age } \\
\text { (years) }\end{array}$ & Gender & PMD (h) & $\begin{array}{c}\text { Braak's } \\
\text { NFT Stage }\end{array}$ \\
\hline \multicolumn{5}{c}{ Brain samples used in SDS-PAGE analyses } \\
\hline Control & 84 & Male & 32 & - \\
Control & 71 & Female & 15 & - \\
Control & 55 & Male & 25 & - \\
Control & 78 & Male & 35 & - \\
Control & 61 & Male & 20 & - \\
Control & 74 & Female & 49 & - \\
ALS & 62 & Female & 44 & - \\
ALS & 55 & Male & 21 & - \\
ALS & 62 & Female & 21 & - \\
\hline AD & 81 & Female & 60 & IV \\
AD & 80 & Male & 23 & V \\
AD & 65 & Male & 70 & V \\
AD & 80 & Female & 51 & V \\
AD & 84 & Female & 81 & V \\
\hline
\end{tabular}


Table 1. Cont.

\begin{tabular}{|c|c|c|c|c|}
\hline & $\begin{array}{c}\text { Age } \\
\text { (years) }\end{array}$ & Gender & PMD (h) & $\begin{array}{c}\text { Braak's } \\
\text { NFT Stage }\end{array}$ \\
\hline $\mathrm{AD}$ & 78 & Female & 18 & VI \\
\hline $\mathrm{AD}$ & 65 & Female & 41 & VI \\
\hline $\mathrm{AD}$ & 81 & Male & 19 & VI \\
\hline $\mathrm{AD}$ & 75 & Female & 7 & VI \\
\hline $\mathrm{AD}$ & 89 & Female & 26 & VI \\
\hline $\mathrm{AD}$ & 93 & Female & 21 & VI \\
\hline $\mathrm{AD}$ & 91 & Female & 34 & VI \\
\hline $\mathrm{AD}$ & 55 & Female & 58 & VI \\
\hline $\mathrm{AD}$ & 81 & Female & NA & VI \\
\hline $\mathrm{AD}$ & 79 & Male & 31 & VI \\
\hline $\mathrm{AD}$ & 82 & Female & NA & VI \\
\hline $\mathrm{AD}$ & 86 & Male & 32 & VI \\
\hline \multicolumn{5}{|c|}{ Brain-derived slices used in immunohistochemistry analyses } \\
\hline Control & 62 & Female & NA & - \\
\hline ALS & 62 & Female & NA & - \\
\hline ALS & 55 & Male & NA & - \\
\hline ALS & 68 & Female & NA & - \\
\hline $\mathrm{AD}$ & 77 & Female & NA & III \\
\hline $\mathrm{AD}$ & 55 & Female & NA & IV \\
\hline $\mathrm{AD}$ & 65 & Male & NA & $\mathrm{V}$ \\
\hline $\mathrm{AD}$ & 84 & Female & NA & $\mathrm{V}$ \\
\hline $\mathrm{AD}$ & 82 & Male & NA & $\mathrm{V}$ \\
\hline $\mathrm{AD}$ & 80 & Male & NA & $\mathrm{V}$ \\
\hline $\mathrm{AD}$ & 86 & Male & NA & VI \\
\hline $\mathrm{AD}$ & 63 & Female & NA & VI \\
\hline $\mathrm{AD}$ & 79 & Male & NA & VI \\
\hline
\end{tabular}

PMD: Post mortem delay, h: hours, NA: Not available. Controls are brain samples isolated from patients diagnosed as negative for several neuropathologies. ALS are control brains samples diagnosed as negative for AD pathology obtained from post-mortem patients diagnosed with amyotrophic lateral sclerosis (ALS). \# Braak and Braak's NFT (neurofibrillary tangle: Tau-related pathology) stage, (-) means no NFT detection.

\subsection{Lentiviruses Production}

Lentiviruses were obtained by co-transfecting the transfer vector with two helper plasmids, $\Delta 8.9$ (packaging vector) and VSV-G (envelope vector) into Lenti-X $293 \mathrm{~T}$ cell line (632180; Clontech, Mountain View, CA, USA). Viral particles were purified from the culture medium, and viral titers were determined by p24 ELISA (VPK-107; Cell Biolabs, San Diego, CA, USA).

\subsection{Cell Lines, Lentiviruses Infection, Transfections and Treatments}

Human SH-SY5Y neuroblastoma cells (CRL-2266, ATCC), and murine microglial cells (BV2) [15] were cultured following the manufacturer's instructions. SH-SY5Y cells stably expressing empty pcDNA3.1 vector (Control), or the human $\beta$ APP harboring the double Swedish mutations cDNA (APPswe: APPKM670/671NL) were already described [16].

SH-SY5Y and BV2 cells were transduced with Green, S1T-Green or SERCA1-Green lentiviruses (cloned in the lentiviral vector with an IRES- ZsGreen fluorescent tag (pHAGE-CMV-MCS-IRES-ZsGreen), under the control of CMV promoter) using five MOI (multiplicity of infection) (48h in BV2 cells and 72-96h in SH-SY5Y cells).

We also used pcDNA 3.1, GFP targeted to the ER (ER-GFP), and GFP fused constructs SERCA1-GFP and S1T-GFP previously described [14]. Transient transfection of cells was carried out using Lipofectamine 2000 reagent (Invitrogen). Cells were treated overnight for the indicated time with thapsigargin $(0.1,0.5$ or $1 \mu \mathrm{M})$, tunicamycin $(10 \mu \mathrm{g} / \mathrm{mL})$ or amyloid $\beta$ oligomers (Aßo) $5 \mu \mathrm{M}$ 
(as already described [17]). Human synthetic $A \beta_{1-42}$ (Bachem AG, Switzerland) was prepared as already described [18].

\subsection{Animal Models}

All applicable international, national, and/or institutional guidelines for the care and use of animals were followed. All procedures performed in studies involving animals were in accordance with the ethical standards of the institution or practice at which the studies were conducted.

In vivo experiments were performed in accordance with the regulations of the Institutional Animal Care and Use Committee of the guidelines established by the European community council (Directive of 24th November 1986), and approved by Nice university Animal care and use Committee, and the National Council on animal care of the Ministry of Health (Project $n^{\circ}$ : NCE/2013-152).

Also, 3xTg-AD mice [19] were housed in the specific-pathogen-free animal facility with a 12:12 $\mathrm{h}$ light/dark cycle and were given free access to food and water.

For biochemical analyses, mice were anesthetized with a ketamine/xylazine $(87 \mathrm{mg} / \mathrm{mL}$ and $13 \mathrm{mg} / \mathrm{mL}$ respectively, $1 \mathrm{~mL} / \mathrm{kg}$ ) mixture and transcardially perfused with PBS for $5 \mathrm{~min}$. Brains were then isolated and stored in the RNA stabilization reagent (RNAlater, Qiagen) for $24 \mathrm{~h}$, and then dried and stored at $-80{ }^{\circ} \mathrm{C}$ until use. For immunohistochemistry analyses, anesthetized mice were perfused with PBS and then with $10 \mathrm{~mL}$ PFA $4 \%$ solution. Brains were post-fixed in PFA $4 \%$ for $24 \mathrm{~h}$. Fixed brains were cut on a vibratome $(50 \mu \mathrm{m})$, or embedded in paraffin, and coronal sections were cut with a sliding microtome $(8 \mu \mathrm{m})$.

\subsection{Stereotaxic Injections and Treatments}

Four-month-old non-transgenic (wild type: WT) and 3xTg-AD mice were anesthetized and then placed in a mouse head holder. Green or S1T-Green lentiviral particles were stereotactically injected bilaterally into the subiculum region $\left(1 \times 10^{10}\right.$ viral particles, $2 \mu \mathrm{L}$ per hemisphere $)$ at the following coordinates $(\mathrm{a} / \mathrm{p},-1.7, \mathrm{~m} / \mathrm{l} \pm 2.5, \mathrm{~d} / \mathrm{v},-3.8)$. After surgery, anesthesia was reversed with atipamezole $(1 \mathrm{mg} / \mathrm{kg})$. Mice were left under a heat lamp for allowing full recovery. Then they were injected with the analgesic buprenorphine at a dose of $0.05 \mathrm{mg} / \mathrm{kg}$ body weight and returned to a clean cage. Biochemical and immunohistochemistry analyses were carried out $4-5$ months after lentiviral injections.

\subsection{Protein Preparations and SDS-PAGE Analysis}

Total proteins and microsomal and mitochondrial fractions were prepared as already described [14]. Intracellular $A \beta$ peptide was detected as already described [16]. Proteins were resolved by $16.5 \%$ Tris/Tricine or $10-12 \%$ Tris/Glycine SDS-PAGE and transferred onto nitrocellulose membranes. Antibodies used are described in Supplementary Table S3. Proteins were visualized using enhanced chemiluminescence and acquired with LAS-4000 imaging system (Fujifilm).

\subsection{Immunohistochemistry and Immunofluorescence}

Human-derived hippocampal and temporal lobe sections and mice-derived slices embedded in paraffin were immunostained after a dewaxing procedure comprising sequential washing steps with xylene, ethanol and PBS. Sections were immunostained with S1T [13] or Iba1 antibodies after antigen unmasking using a Vector Antigen unmasking solution (Vector Laboratories). For 6E10 staining, sections were treated with formic acid ( $90 \%$ for $5 \mathrm{~min}$ ). Serial slices were immunostained with S1T and 6E10 antibodies. Non-specific binding was blocked for $1 \mathrm{~h}$ in 5\% BSA, 0.5\% TBS-Triton X-100 solution. Sections were incubated at $4{ }^{\circ} \mathrm{C}$ overnight with primary antibodies (Supplementary Table S3). Sections were incubated with HRP-conjugated secondary antibodies (Jackson ImmunoResearch) followed by diaminobenzidine (DAB) substrate (Vector). Neuronal nuclei were detected with Cresyl violet. 


\subsection{In Vitro $\beta$-Secretase Assay}

BACE-1 activity corresponding to the $\beta$-secretase inhibitor-sensitive fluorescence was monitored as already described $[16,20]$.

\subsection{Quantitative Real-Time PCR and Amplification S1T}

Total RNA from cells and mice brains were extracted using the RNeasy mini kit and RNeasy universal, respectively (Qiagen, Germany) and then reverse-transcribed with GoScript $\mathrm{t}^{\mathrm{TM}}$ Reverse Transcriptase (Promega, USA) using oligo-dT priming. Real-time PCR was performed in the Rotor-Gene6000 (Qiagen, Germany), using the SYBR Green detection protocol. Specific-gene primers are described in the supplementary material (Supplementary Table S4). Hot start touchdown amplification was performed to amplify S1T as already described [13] using primers on SERCA1 exon10 and exon13 sequences as described in Figure 2C and Supplementary Table S4.

\subsection{Statistical Analyses}

Data were expressed as means \pm SEM. Sample size for each experiment is indicated in the figure captions. Data were analyzed with GraphPad Prism version 7.02 for Windows (GraphPad Software, La Jolla, CA, USA; www.graphpad.com). Data were first analyzed for normal distribution. We used the Mann-Whitney test when the two groups of variables have not passed the normality test. Groups of more than two variables that have passed normality test were analyzed by One-way ANOVA with Dunnett's multiple comparison post-test. Correlations were analyzed with Spearman's correlation coefficient. Significant differences are: ${ }^{*} p<0.05,{ }^{* *} p<0.01,{ }^{* *} p<0.001,{ }^{* * *} p<0.0001$ and ns = non-significant.

\section{Results}

\subsection{S1T Protein Expression is Increased in Human AD Brains}

We first analyzed the expression of S1T in a cohort of sporadic human AD brains and aged-matched non-demented controls (see Table 1 for demographic data and neuropathological status). As expected, we revealed significantly increased levels of $A \beta$ peptide (Figure $1 \mathrm{~A}, \mathrm{~B}$ ) and of hyperphosphorylated Tau protein (P-Tau, Figure 1A,C) in AD brains while full-length $\beta$ APP (Figure 1A,E) remained unchanged. Neurofilament (NF) was also unchanged (Figure 1A,F). Importantly, by using an antibody specifically recognizing S1T protein but not full-length SERCA1 protein [13], we observed a significant increase of the expression of S1T in AD-affected brains (Figure 1A,D). We confirmed this increase with an anti-SERCA1 antibody recognizing the N-terminal sequence of both S1T and full-length SERCA1. We also revealed that full-length SERCA1 isoform appeared poorly expressed in both control and AD brains (Figure 1A). Additionally, we revealed that S1T expression levels correlated with both $\mathrm{A} \beta$ (Figure 1G) and P-Tau (Figure 1H) levels. These biochemical observations were strengthened by immunohistochemical analysis that revealed an increased staining of S1T in AD brain slices as compared to controls (Figure 1I, Table 1, and Supplementary Table S1). We classified S1T staining intensity as high or low (as shown in representative images in Figure 1I). These analyses showed that high-intensity staining of S1T was associated with focal A $\beta$ deposits while low S1T staining was observed in samples displaying diffuse plaques (Supplementary Table S1), thus corroborating our biochemical observations linking high S1T expression to elevated levels of $A \beta$. We also observed an increased expression of S1T in the hippocampus of AD-derived brains as compared to controls (Supplementary Figure S1, and Supplementary Table S2). Overall, this set of data suggests a consistent increase of S1T isoform expression in various brain areas of a large cohort of late-stage sporadic AD-affected human brains. 
A
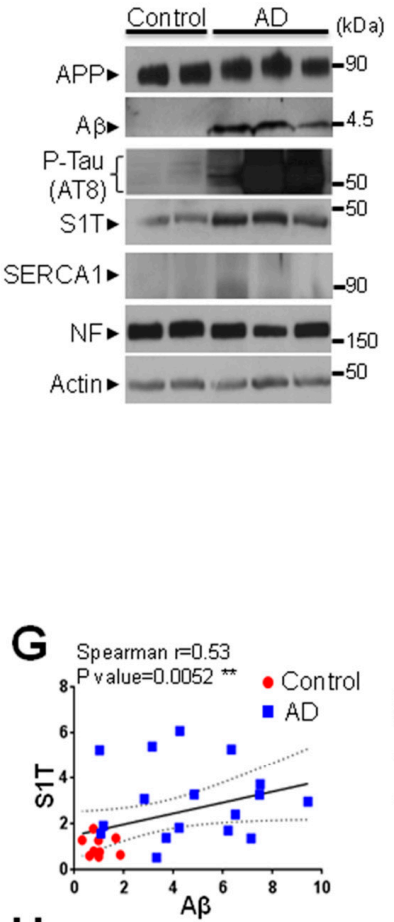

$\mathrm{H}$

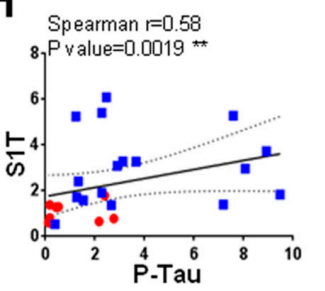

B
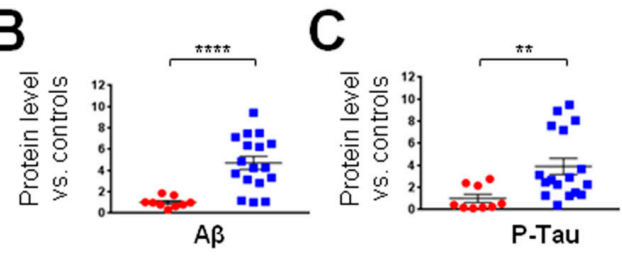

D
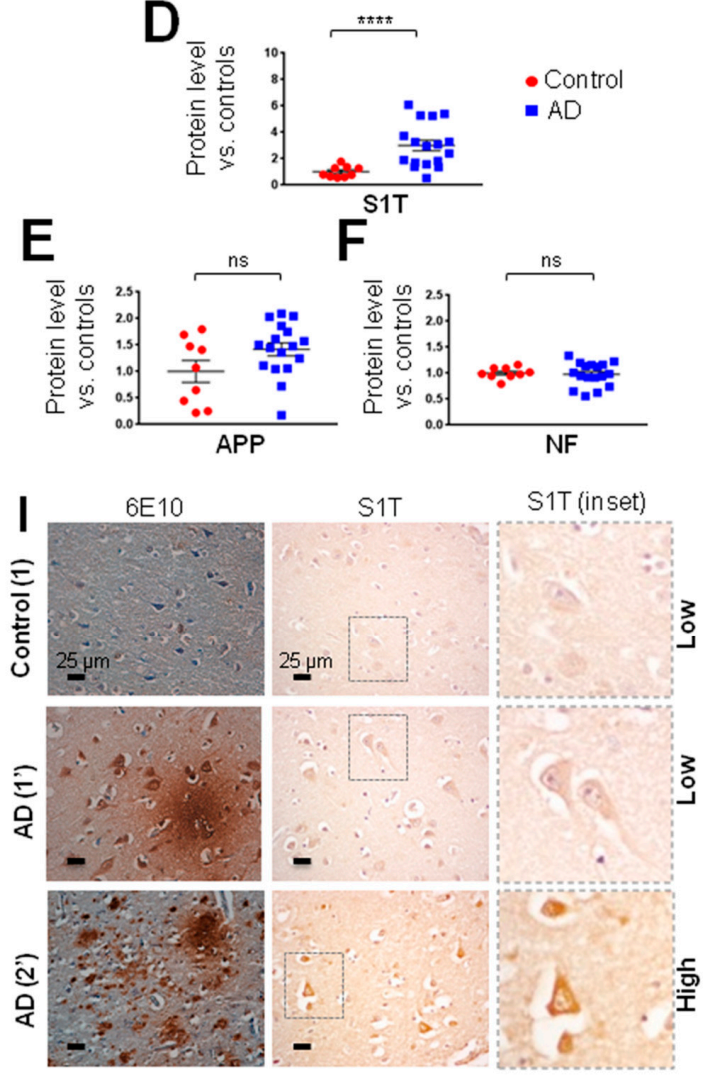

Figure 1. S1T expression is increased in human AD-affected brains. (A) Representative SDS-PAGE showing the expression pattern of S1T, APP, A $\beta$, Hyperphosphorylated Tau (P-Tau), Neurofilament (NF) in the temporal lobe of human AD brains (Braak's stage IV, V and VI) ( $\mathrm{n}=17)$ as compared to aged-matched non-demented controls $(n=9)$. Demographic data and neuropathological status of brain samples are reported in Table 1. $\beta$ APP and A $\beta$ were detected using 6 E10 antibody (recognizing amino acids 1-16 of A $\beta$ ). Hyperphosphorylated Tau was detected by using AT8 antibody (recognizing phosphorylated (serine 202 and threonine 205) protein helical filament Tau, but not unphosphorylated Tau). Neurofilament (NF) and Actin were used as loading controls. S1T was detected using a homemade antibody recognizing a specific epitope in S1T protein directed towards the $\mathrm{COOH}$-terminal 10 amino acid generated by exon 11 splicing [13]. SERCA1 was detected using an antibody recognizing $\mathrm{N}$-terminal epitope. (B-F) Graphs represent means \pm SEM of protein expression levels analyzed versus mean control values considered as 1 . $^{* * * *} p$-value $<0.0001,{ }^{* *} p$-value $<0.01$, and (ns) non-significant versus control using the Mann-Whitney test. $(\mathbf{G}, \mathbf{H})$ Correlation analyses between S1T expression and A $\beta$ or P-Tau. Statistical Spearman $r$ values and $p$-values were obtained using both control and AD individuals' data. The regression line (dotted lines representing the $95 \%$ confidence interval) is based on merged data. (I) Immunohistochemical detections of $\beta$ APP-derived fragments and of A $\beta$ plaques with $6 \mathrm{E} 10$ antibody or of S1T in the temporal lobe of human AD $(n=9)$ and of aged-matched non-demented control brains $(n=4)$. Demographic data and neuropathological status of brain samples are reported in Table 1. S1T staining intensity and A $\beta$ plaque type are reported in Supplementary Table S1. Nuclei were revealed using Cresyl Violet dye in 6E10 stained slices. The insets show S1T positive neurons. Scale bar $25 \mu \mathrm{m}$. Control (1), and AD (1' and $\left.2^{\prime}\right)$ are referenced in Supplementary Table S1 and are representative samples harboring low or high $\mathrm{S} 1 \mathrm{~T}$ immunostaining. 


\subsection{ER Stress-Associated PERK-eIF2 $\alpha$-ATF4 Pathway Is Modulated in Human AD Brains}

We previously reported that S1T is induced under pharmacological and physiopathological ER stress conditions through the PERK-eIF2 $\alpha$-ATF4 pathway [14]. We thus analyzed the expression of ER stress markers belonging to this pathway in our sporadic human AD-derived brains cohort. We observed a significant increase of the expressions of ATF4 (Figure 2A,E), GRP78 (Figure 2A,F), and calreticulin (CRT) (Figure 2A,H) in AD brains as compared to controls, while the ubiquitous SERCA2b isoform (Figure 2A,B), p-eIF2 $\alpha$ (Figure 2A,C), and GRP94 (Figure 2A,G) expressions remained unchanged. A slight but a significant decrease of CHOP protein was also observed in AD-derived brain samples (Figure 2A,D). We further revealed that increases of CRT and to a lesser extent GRP78, positively correlate with A $\beta$ or S1T levels (Figure 2I-L) while correlation analyses between CHOP, ATF4, GRP94, and p-eIF2 $\alpha$ proteins and A $\beta$ or S1T levels failed to reach statistical significance (data not shown). All over, these data revealed for the first time an increased level of S1T protein in sporadic AD brains correlating with ER chaperones GRP78 and CRT (Figures 1 and 2).

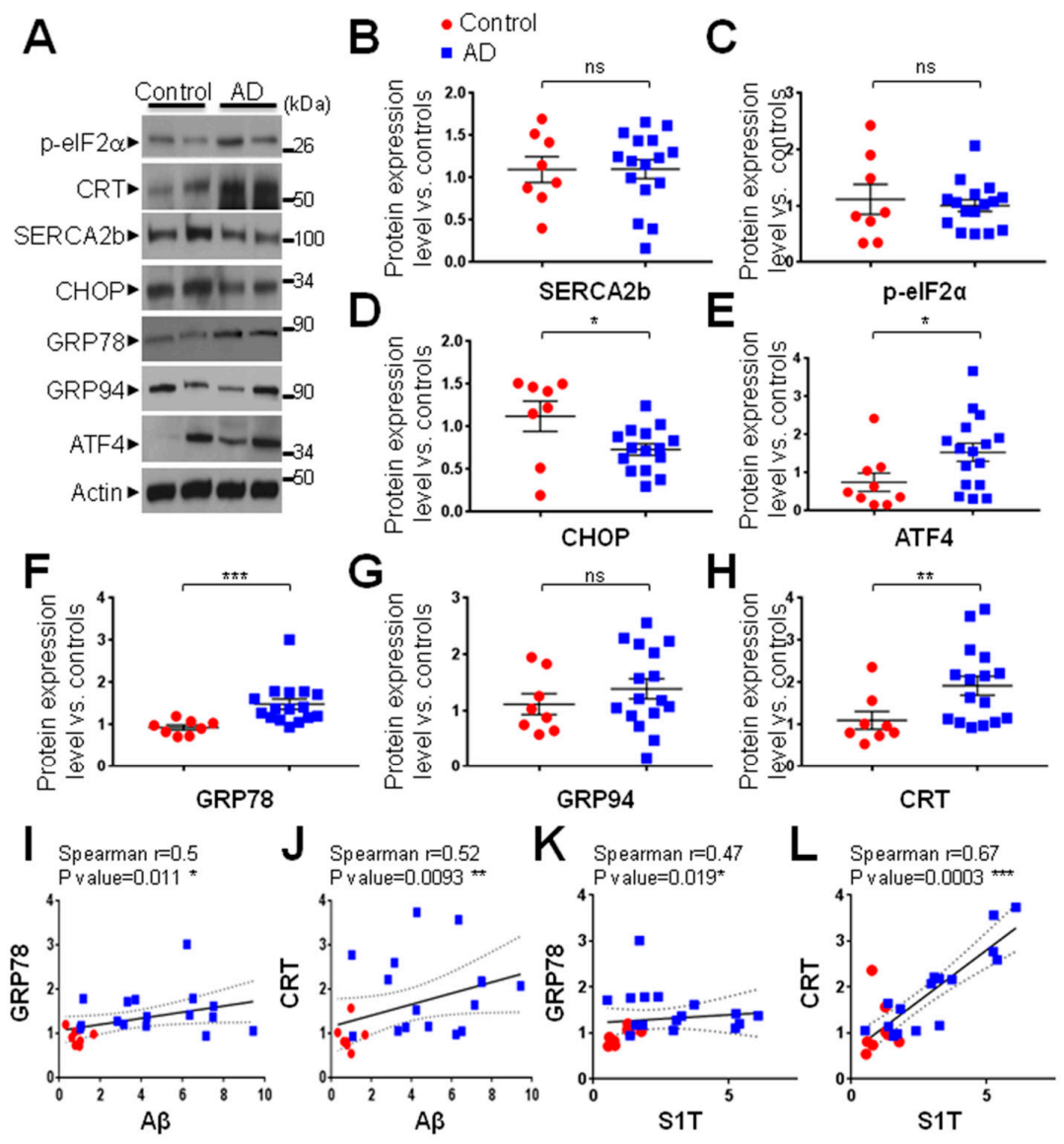

Figure 2. Expression of ER stress markers in human AD-affected brains. Demographic data and neuropathological findings of brain samples are reported in Table 1. (A) Representative SDS-PAGE showing the expression pattern of p-eIF2 $\alpha$, Calreticulin (CRT), SERCA2b, CHOP, glucose-regulated protein 78 (GRP78) and 94 (GRP94), and ATF4 in the temporal lobe of human AD-affected brains $(\mathrm{n}=15-16)$ as compared to age-matched non-demented controls $(\mathrm{n}=8-9)$. Actin was used as a loading control. (B-H) Graphs represent means \pm SEM protein expression levels analyzed versus mean control values considered as 1 . $^{* * *} p$-value $<0.001,{ }^{* *} p$-value $<0.01,{ }^{*} p$-value $<0.05$, and (ns) non-significant versus control using the Mann-Whitney test. (I-L) Correlation analyses of GRP78 (I,K), and CRT (J,L) expression levels with A $\beta(\mathbf{I}, \mathbf{J})$ or S1T $(\mathbf{K}, \mathbf{L})$. Statistical Spearman $r$ values and $p$-values were obtained using both control and AD individual's data. The regression line (dotted lines representing the $95 \%$ confidence interval) are based on merged data. 
3.3. S1T Protein Expression is Increased in Human SH-SY5Y Cells Expressing APPswe or Treated by Oligomeric $A \beta$

We then investigated expressions of S1T and ER stress markers in the neuroblastoma SH-SY5Y cell line stably expressing the Swedish mutated APP (APPswe: SH-SY5Y APPswe). This mutation was previously shown to enhance $\beta$-secretase-mediated cleavage of $\beta$ APP, thereby increasing productions of the $\beta$ APP C-terminal fragment $C 99$, and subsequently A $\beta$ peptides [16]. We confirmed the overexpression of full-length $\beta$ APP and enhanced production of $A \beta$ in APPswe expressing cells as compared to mock-transfected control cells (Figure 3A,B). Importantly, we observed increased expressions of S1T protein (Figure 3A,C), CRT, GRP78, GRP94 (Figure 3A,D), and p-eIF2 $\alpha$ (Figure 3A,E) in APPswe-expressing cells, while (as observed in human brains), the ubiquitous SERCA2b isoform expression remained unchanged (Figure $3 \mathrm{~A}, \mathrm{C}$ ). Unlike what was observed in AD brains, we did not observe any significant modification of the expression of CHOP and ATF4 (data not shown).

Several lines of evidence indicate that oligomeric $A \beta$ could act as a neurotoxic trigger in $\mathrm{AD}$ pathology through the induction of ER stress [21]. In accordance with previous studies, we used soluble synthetic $A \beta 42$ oligomers $(\mathrm{oA} \beta)$ as a toxic trigger [22,23], and specific set of primers allowing the amplification of both SERCA, and S1T transcripts (Figure 3F). S1T mRNA was increased in oA $\beta$-treated SH-SY5Y cells as compared to non-treated (NT) cells (Figure 3G), as illustrated by an increased S1T/SERCA1 mRNA ratio (Figure 3I). We also observed an increase of CHOP transcript level and a slight but significant decrease of GRP78 mRNA upon oA $\beta$ treatment (Figure 3J). This agrees with previous studies showing that oA $\beta$ exposure modulates the expression of GRP78 and CHOP at the mRNA and protein levels in a time-dependent manner in SH-SY5Y cells [24]. As controls, we revealed that pharmacological ER stress induction by thapsigargin (TG) (a specific inhibitor of SERCA proteins) increased S1T/SERCA1 mRNA ratio (Figure 3H,I) as well as GRP78 and CHOP mRNAs levels (Figure 3J). Together, our data unraveled a consistent induction of S1T in neuroblastoma cells endogenously producing $\beta$ APP-derived fragments (APPswe cells) or exogenously treated with $\mathrm{A} \beta$ oligomers. 
A

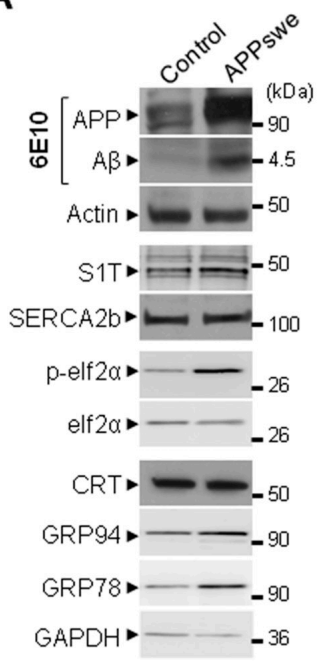

$\mathbf{F}$
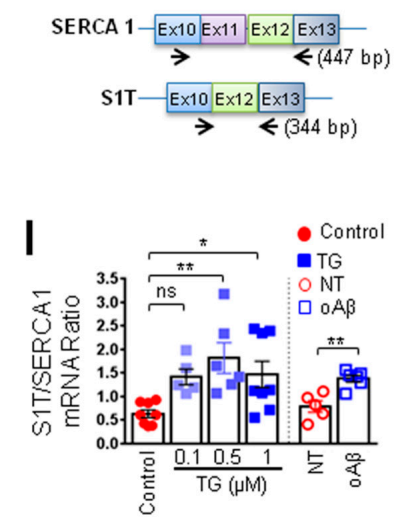
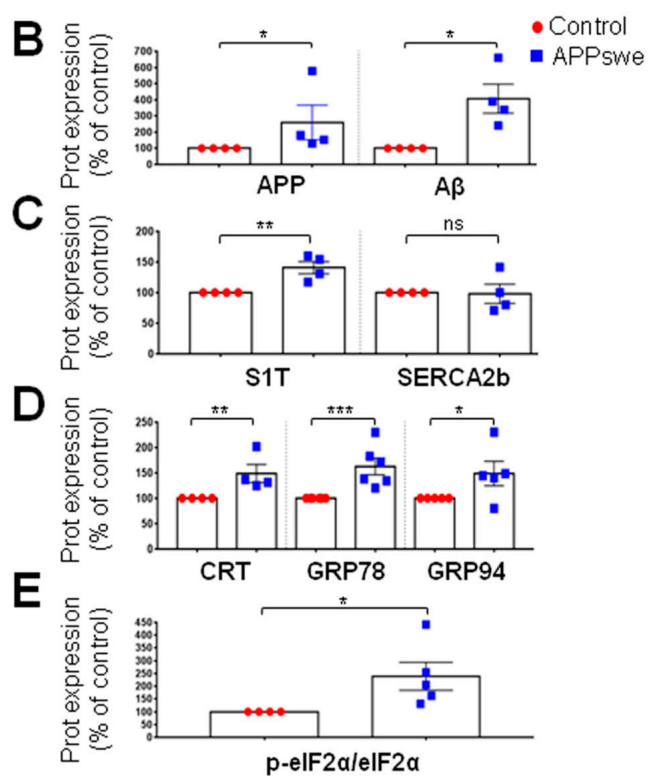

G

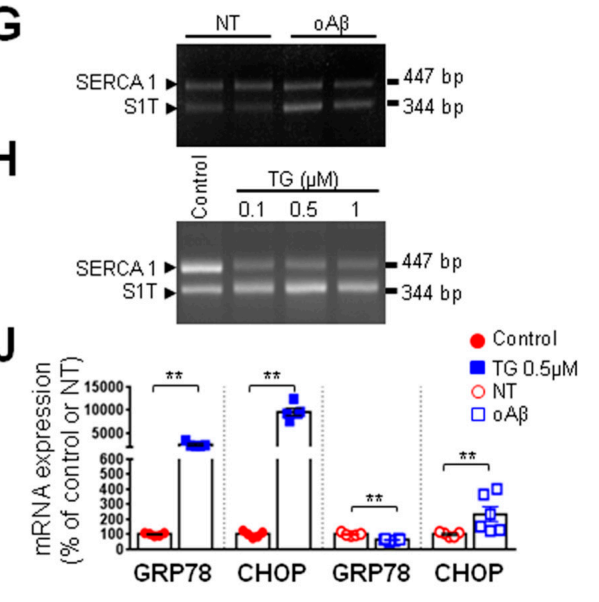

Figure 3. S1T expression is increased in the SH-SY5Y cells expressing APPswe and in SH-SY5Y cells treated with oligomeric $\mathrm{A} \beta$ peptides. (A) Representative SDS-PAGE showing the expression pattern of $\beta$ APP, A $\beta$ as detected using 6E10 antibody, and of S1T and ER stress markers (SERCA2b, p-eIF2 $\alpha$, eIF2 $\alpha$, CRT, GRP78 and GRP94 in SH-SY5Y cells expressing pcDNA3.1 empty vector (Control) or APPswe construct (APPswe). Actin or GAPDH were used as loading controls. (B-E) Graphs represent means \pm SEM of protein expression levels analyzed versus mean control values considered as $100 \%$ and obtained in 4-6 independent experiments. ${ }^{* * *} p$-value $<0.001,{ }^{* *} p$-value $<0.01,{ }^{*} p$-value $<0.05$, and (ns) non-significant versus control using the Mann-Whitney test. (F) Position of the primers (on exons 10 and 13) used to amplify SERCA1 transcripts with (447 bp: SERCA1) or without (344 bp: S1T) exon 11. (G,H) Representative gels of RT-PCR of SERCA1 and S1T expression patterns in SH-SY5Y cells non-treated (NT) or treated with oligomeric $A \beta$ peptides $(\mathrm{oA} \beta)(5 \mu \mathrm{M})(\mathrm{G})$, or treated with vehicle (Control) or thapsigargin (TG) $(0.1,0.5$, and $1 \mu \mathrm{M})$ for $20 \mathrm{~h}(\mathbf{H})$. (I) Graph represents means \pm SEM of S1T/SERCA mRNA ratio obtained in at least 4 independent experiments. ${ }^{* *} p$-value $<0.01,{ }^{*} p$-value $<0.05$, and (ns) non-significant versus control using the one-way ANOVA and Dunnett's post-test, or versus NT using the Mann-Whitney test. (J) Quantitative RT-PCR of GRP78 and CHOP in SH-SY5Y cells treated with $\mathrm{A} \beta$ oligomers as in $(\mathbf{G})$ or with $0.5 \mu \mathrm{M}$ of TG $(\mathbf{H})$. Genes were normalized for RNA concentrations with topoisomerase1 and GAPDH. The graph represents means \pm SEM mRNA levels analyzed versus mean control or NT values taken as $100 \%$. ${ }^{* *} p$-value $<0.01$, versus control or NT using the Mann-Whitney test. 
3.4. Expression of S1T Protein Enhances Amyloidogenic Processing of $\beta A P P$ through Increased BACE1 Expression and Activity

We generated lentivirus-based stable SH-SY5Y APPswe cell lines expressing S1T or SERCA1 cDNA simultaneously with the ZsGreen protein under IRES cassette. These constructs allow easy in situ detection after cell transduction (Figure 4A). S1T and SERCA1 overexpressions were also biochemically validated in microsomal protein extracts prepared from SH-SY5Y APPswe cells (Figure 4B).

We examined the potential modulation of $\beta \mathrm{APP}$ processing by S1T by analyzing the level of intracellular $\beta$ APP-derived fragments. As shown in the representative SDS-PAGE (Figure 4B,C) and quantitative analyses (Figure 4D), S1T but not SERCA1 overexpression increased the production of all intracellular $\beta$ APP-derived fragments (C83, C99, A $\beta$, and AICD). Importantly, this was not due to increased full-length $\beta$ APP level (Figure 4C,D).

Further, we showed that S1T overexpression led to the accumulation of $\beta$ APP-derived fragments in the mitochondrial fraction (Supplementary Figure S2A,B).

We then investigated the potential implication of S1T in the modulation of non-amyloidogenic metabolism of $\beta$ APP. Neither S1T nor SERCA1 altered the production of the soluble sAPP $\alpha$ derived from the cleavage of $\beta$ APP by $\alpha$-secretase (Supplementary Figure S3A,B). Accordingly, the expression of constitutive $\alpha$-secretase (ADAM10) was not affected by S1T and SERCA1 (Supplementary Figure S3C,D).

Amyloidogenic metabolism of $\beta$ APP implies its sequential cleavage by $\beta$ - and $\gamma$-secretases [25]. Thus the increase of $C 99$ and $A \beta$ peptide production upon S1T overexpression may be linked to the increased expression and/or activity of $\beta$ - and/or $\gamma$-secretases. We showed that SH-SY5Y APPswe stably expressing S1T but not SERCA1 displayed increased expression of BACE1 (Figure 4E,F). Accordingly, we then revealed that S1T but not SERCA1 triggered a significant increase of the $\beta$-secretase specific activity in APPswe expressing cells (Figure 4G). The analyses of the expression of components of the $\gamma$-secretase complex [26] (Pen 2, Aph1, Nicastrin, PS1, and PS2) (Supplementary Figure S4A-F) revealed an unchanged level of PS1 (the catalytic core of the $\gamma$-secretase complex) in S1T expressing cells (Supplementary Figure S4A-F). Accordingly, we did not observe any significant modulation of the $\gamma$-secretase activity as analyzed in reconstituted membranes prepared from APPswe cells expressing S1T or SERCA1 proteins (Supplementary Figure S4G). Overall, these data reveal that enhanced $\beta$-amyloidogenic processing of $\beta$ APP upon S1T expression is specifically linked to the modulation of BACE1 expression and activity. Thus, the enhanced $\alpha$-secretase-derived C83 fragment is likely due to an enhanced level of its precursor C99 fragment [27]. 


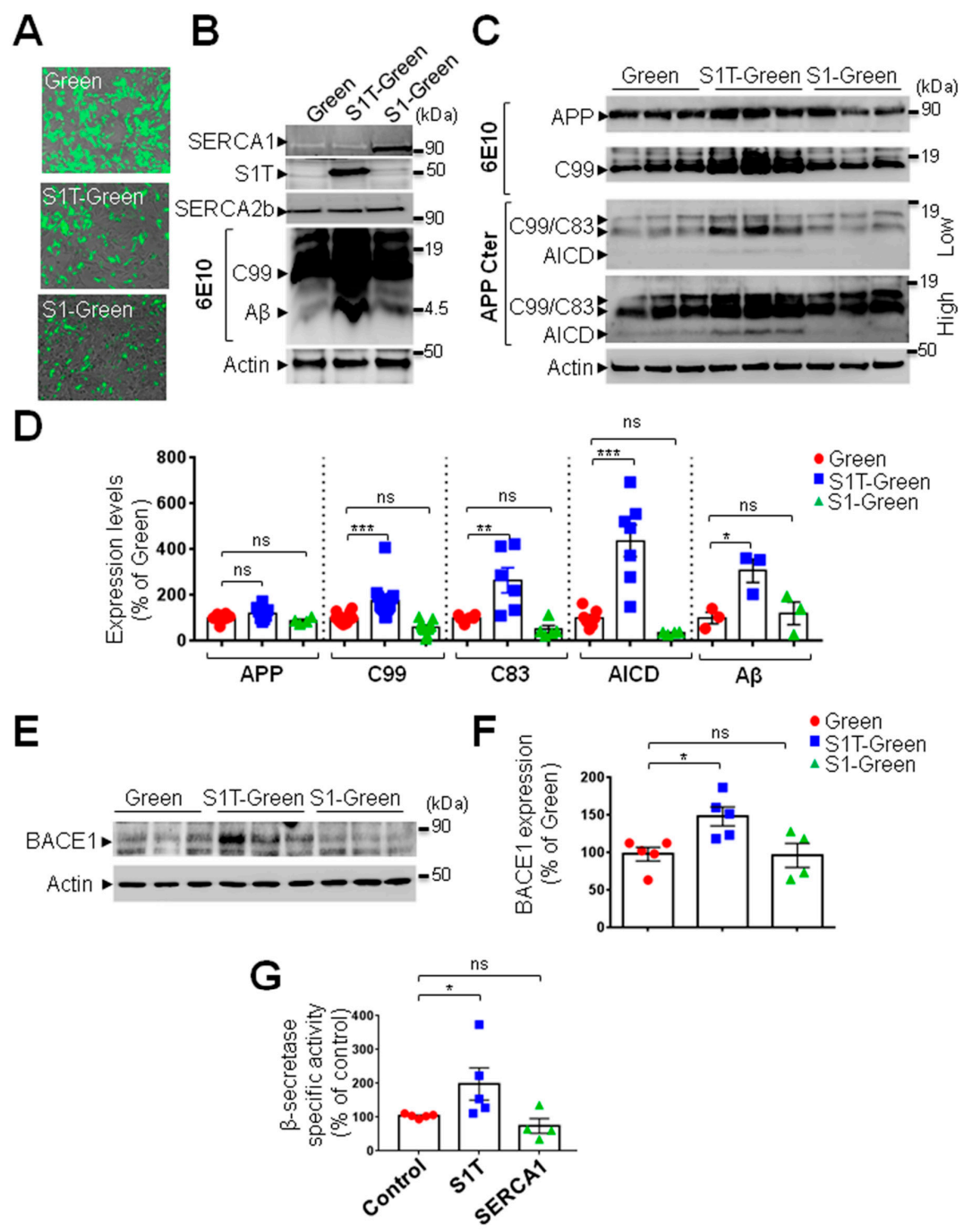

Figure 4. S1T overexpression enhances amyloidogenic $\beta$ APP processing. (A) Representative images of SH-SY5Y APPswe lentivirus-mediated stable Green, S1T-Green and SERCA1-Green cell lines. (B) Representative SDS-PAGE showing the expression patterns of SERCA1, S1T (detected with SERCA1 $\mathrm{N}$-terminal antibody) and of $\beta$-secretase C-terminal APP-derived fragment (C99) and A $\beta$ (detected with 6E10 antibody) in SH-SY5Y APPswe transduced cells. SERCA2b and actin were used as loading controls. (C) Low and high exposures of representative SDS-PAGE showing the expression pattern of full-length $\beta$ APP and C99 (detected with 6E10 antibody), and C99 and C83 ( $\alpha$-secretase-derived APP C-terminal fragment) and APP intracellular domain (AICD) as detected using an antibody recognizing APP C-terminal epitope (APP-Cter). Actin was used as a loading control. (D) The graph represents means \pm SEM of protein expression levels analyzed versus mean control values (Green) considered as $100 \%$ and obtained in at least 4 independent experiments. ${ }^{* * *} p$-value $<0.001,{ }^{* *} p$-value $<0.01$, * $p$-value $<0.5$, and (ns) non-significant versus control using the one-way ANOVA and Dunnett's post-test. (E) Representative SDS-PAGE showing BACE1 expression in SH-SY5Y APPswe cells transduced with Green, S1T-Green and SERCA1-Green lentiviruses. Actin was used as a loading control. (F) The graph represents means \pm SEM of BACE1 expression level versus mean control values (Green) considered as $100 \%$ and obtained in at least 4 independent experiments. ${ }^{*} p$-value $<0.05$, and (ns) non-significant versus Green using the one-way ANOVA and Dunnett's post-test. (G) The graph represents the means \pm SEM of the specific activity of $\beta$-secretase in SH-SY5Y APPswe cells transfected with ER-GFP (Control), S1T-GFP (S1T), SERCA1-GFP (SERCA1). $\beta$-secretase specific activity is shown as $\%$ of mean control values considered as $100 \%$. ${ }^{*} p$-value $<0.05$, and (ns) non-significant versus control using the one-way ANOVA and Dunnett's post-test. 


\subsection{Lentiviral Expression of S1T Enhances $\beta$-Secretase-Mediated APP Processing In Vivo}

The level of basal expression of S1T was not significantly enhanced in 3xTg-AD mice at different ages as compared to age-matched wild type mice (Supplementary Figure S5A,B). This observation was further confirmed in a second AD mice model, the Tg2576 mice (Supplementary Figure S5C). These data reveal a specific induction of S1T in human-derived cells and brains. Thus, we sought to investigate the impact of S1T overexpression in vivo through bilateral stereotaxic injection of lentiviral particles expressing S1T-Green or Green proteins in the subiculum of 3xTg-AD mice and their controls (Figure 5A,B). We confirmed the expected expression of Green protein (Figure 5C,D) and that of S1T in the subiculum of injected mice (Figure 5D,E). Interestingly, we observed that S1T overexpression enhanced the production of the C99 fragment in 3xTg-AD mice (Figure 5D,F).

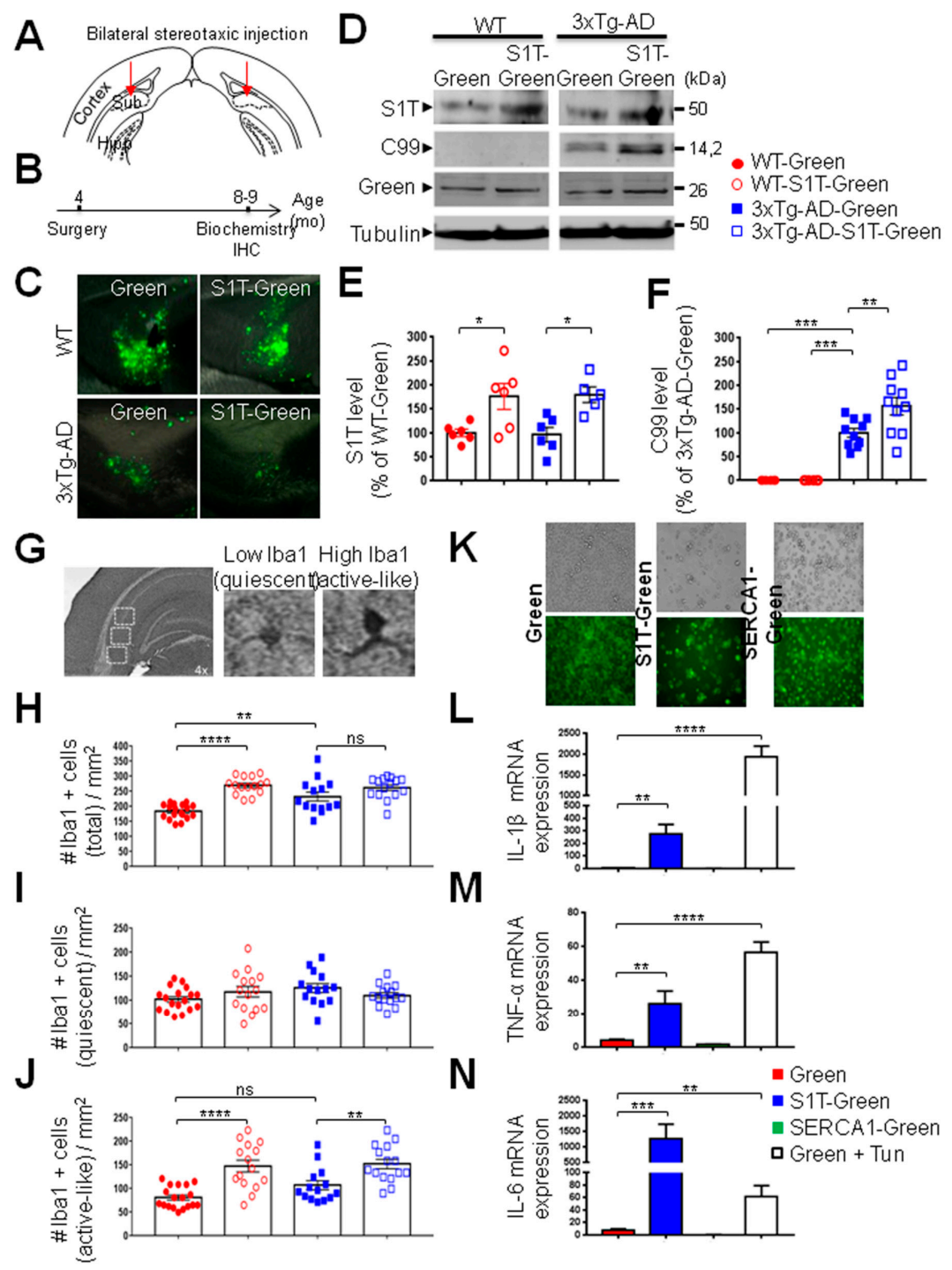

Figure 5. Lentivirus-mediated S1T delivery increases C99 production and triggers neuroinflammation in the 3xTg-AD mice. (A) Bilateral stereotaxic injection of lentiviruses (Green or S1T-Green) into the hippocampus (subiculum region) of 3xTg-AD and non-transgenic control mice (wild type: WT). (B) Timeline of lentiviral injection (mice aged 4 months-old) and of subsequent biochemical analysis and immunohistochemistry of mice (mice aged 8-9 months-old). (C) Representative coronal brain slices showing Green-positive cells (green) in injected mice. (D) Representative SDS-PAGE showing S1T, C99, and Green protein expression in injected mice. Tubulin was used as a loading control. (E) The graph represents the means \pm SEM of S1T expression expressed as the percent of control WT mice considered 
as 100\% (WT-Green $(\mathrm{n}=6)$; WT-S1T-Green $(\mathrm{n}=6)$, 3xTg-AD-Green $(\mathrm{n}=6)$, and 3xTg-AD-S1T-Green $(\mathrm{n}=5) .{ }^{*} p$-value $<0.05$ versus WT-Green or 3xTg-AD-Green using the one-way ANOVA and Tukey's post-test. (F) The graph represents the means \pm SEM of C99 level versus the mean value in 3xTg-AD mice injected with Green lentivirus considered as $100 \%$. ${ }^{* * *} p$-value $<0.001$, and ${ }^{* *} p$-value $<0.01$ versus 3xTg-AD-Green using the one-way ANOVA and Dunnett's post-test. (G) The number of total, quiescent, and activated microglia was recorded in three fields in the subiculum of injected mice. Quiescent microglia (low Iba1 staining and ramified microglia) and activated-like microglia (high Iba1 staining with thickened processes) were identified in separate fields in 3 different mice in each group. $(\mathbf{H}-\mathbf{J})$ Quantification of the total number $(\mathbf{H})$, quiescent $(\mathbf{I})$, and active-like Iba1 positive cells $/ \mathrm{mm}^{2}(\mathbf{J})$. **** $p$-value $<0.0001$, and ${ }^{* *} p$-value $<0.01$, and (ns) non-significant versus WT-Green or 3xTg-AD-Green using the one-way ANOVA and Dunnett's post-test. (K-N) Expression of S1T enhances the expression of proinflammatory cytokines in BV2 microglial cells. (K) Representative images showing BV2 cells infected with Green, S1T-Green or SERCA1-Green lentiviruses. (L-N) RT-PCR analysis of mRNA expression of IL1- $\beta(\mathbf{G})$, TNF- $\alpha(\mathbf{M})$, and IL-6 (N). BV2 cells treated with tunicamycin (Tun) at $10 \mu \mathrm{g} / \mathrm{mL}$, $16 \mathrm{~h}$ were used as control. The relative expression levels of mRNAs are represented as the means \pm SEM versus the mean value in Green expressing cells (control) considered as 1 and obtained in 4 independent experiments in duplicates. ${ }^{* * *} p$-value $<0.0001,{ }^{* * *} p$-value $<0.001$, and ${ }^{* *} p$-value $<0.01$ versus Green using the one-way ANOVA and Dunnett's post-test.

3.6. Lentiviral Expression of S1T Protein Activates Microglia In Vivo and Enhances Proinflammatory Gene Expression in Cells

In addition to coordinating the expression of stress response genes during ER stress, the UPR initiates inflammatory pathways essential for the innate immune response $[5,28]$. Thus, we investigated the potential implication of S1T expression in neuroinflammation and focused on microglia activation. We analyzed proliferative activity and morphological changes (the main characteristic properties of active microglia) in both control and 3xTg-AD injected mice (as described in Figure 5A). In three areas of the subiculum (Figure 5G), we quantified the number of total microglia, quiescent ramified microglia characterized by low Iba1 intensity staining, and active-like microglia characterized by high Iba1 intensity staining with thickened processes and irregular cell bodies (see representative images in Figure 5G).

We observed an increased proliferative activity of microglia in 3xTg-AD mice as compared to control mice injected with Green lentivirus, as well as a significant increase of the number of total microglia in wild type mice upon S1T expression (Figure 5H). We also unraveled an increased active-like microglia in both wild type and 3xTg-AD mice injected with S1T lentivirus (Figure 5J), while the number of quiescent microglia between the different groups remained unchanged (Figure 5I). As a control, we performed the same analyses in a pharmacological model of ER stress obtained by intraperitoneal injection of tunicamycin in young wild type mice (Supplementary Figure S6). Tunicamycin treatment increases p-eIF2 $\alpha$, CHOP and calreticulin levels (Supplementary Figure S6A,B). Interestingly, as was seen upon S1T expression, we observed an enhanced number of total and activated microglia in tunicamycin-treated mice (Supplementary Figure S6C-E), while the number of quiescent microglia remained unchanged (Supplementary Figure S6F).

We further demonstrate the potential implication of S1T and of ER stress in neuroinflammatory response and revealed a significant increased expression of interleukin $1 \beta$ (IL1- $\beta$ ) (Figure 5L), tumor necrosis $\alpha$ (TNF- $\alpha$ ) (Figure 5M), and interleukin 6 (IL-6) (Figure 5N) in BV2 cells upon S1T-Green expression (Figure $5 \mathrm{~K}$ ), or treatment with tunicamycin, but not upon SERCA1-Green expression (Figure 5K-N). Importantly, we also reported enhanced IL1- $\beta$, TNF- $\alpha$, and IL-6 mRNA levels in vivo in tunicamycin-treated mice (Supplementary Figure S5G). Altogether, both in vivo and in vitro approaches demonstrate a regulation of neuroinflammatory response under ER stress conditions triggered by S1T expression or pharmacological challenge. 


\section{Discussion}

Several studies have reported that UPR occurs relatively early in AD and that ER stress sensors PERK and IRE1 $\alpha$ are activated in human AD brains [29,30]. We previously demonstrated that the human S1T isoform is induced under pharmacological and physiopathological ER stress conditions leading to ER stress amplification [14]. UPR activation has been proposed to be linked to intracellular $A \beta$ accumulation [31]. Accordingly, we reveal herein that S1T is upregulated in a cellular AD model overproducing $\beta$ APP-derived catabolites. Importantly, biochemical data indicate that enhanced human S1T expression correlates with $A \beta$ load in human $A D$-affected brains and that $S 1 T$ high immunostaining is selectively observed in human $\mathrm{AD}$ cases harboring focal $\mathrm{A} \beta$ plaques. We further demonstrated that S1T expression is induced by exogenous application of A $\beta$ oligomers in SH-SY5Y cells.

S1T is induced through the activation of the PERK-eIF2 $\alpha$-ATF4-CHOP pathway [14]. We observed an increased expression of $\mathrm{p}$-eIF $2 \alpha$ in SH-SY5Y APPswe cells thus confirming previous studies reporting increased phosphorylation of eIF $2 \alpha$ in both in cellular and in vivo models expressing the APPswe mutation [32]. However, we observed discrepancies for p-eIF2 $\alpha$, ATF4 and CHOP expressions between SH-SY5Y APPswe cells and AD brains. These data may indicate distinct time-dependent regulations of PERK-eIF2 $\alpha$-ATF4-CHOP pathway in cells and in vivo AD study models. Accordingly, we and others reported that UPR genes show a dose- and time-dependent induction, transient decline, and re-induction kinetics under pharmacological ER stress stimuli [14,33]. Moreover, elevations of p-PERK, p-IRE1, and p-eIF2 $\alpha$ in human AD were demonstrated to be brain-area dependent [34], associated with abnormally phosphorylated Tau $[30,34,35]$, and likely more involved at the early stages of AD pathology $[7,30]$. Thus, cellular and mice AD models could not fully recapitulate the pathological alterations observed in human AD progression. According to this possibility, the induction of ER stress response in $\mathrm{AD}$ mice models has been recently questioned [36-38], and we did not reveal any change in the expression of endogenous S1T, nor of the GRP78 level in the 3xTg-AD mice at different ages (Supplementary Figure S5A,B).

We reveal that S1T overexpression increases the accumulation of intracellular $\beta$ APP-derived fragments (C-terminal fragments: CTFs (C99, and C83), A $\beta$, and AICD) in the mitochondrial fraction of APPswe cells. We previously documented an $A \beta$ and $\beta$ APP-CTFs accumulation in mitochondria-associated membranes (MAMs) in both in vitro and in vivo AD models [22]. Other studies showed that these fragments harbor toxic properties toward mitochondria [21,39]. Thus, we propose that S1T-mediated intracellular/mitochondrial accumulations of $\beta$ APP-derived toxic fragments may promote mitochondrial-dependent cell death.

S1T-associated pro-amyloidogenic phenotype is mechanistically linked to increased BACE1 expression and activity with no alterations of $\alpha$ - and $\gamma$-secretases. Several lines of evidence indicated that enhanced phosphorylations of PERK and eIF2 $\alpha$ in the AD brain are associated with increased amyloidogenic $\beta$ APP processing [32,40,41] through increased BACE1 expression [42,43]. Altogether, and as reviewed in [44], our data strengthen the molecular link between ER stress and BACE1.

The three UPR branches converge on activating NF- $\mathrm{KB}$, thus driving the expression of cytokines (TNF $\alpha$, IL-1, IL-6 and IL-8) [28], accordingly, we demonstrate herein that S1T overexpression, as well as tunicamycin treatment, induce the expression of proinflammatory cytokines and increase proliferation and active microglia. Tunicamycin induces ER stress response and enhances S1T expression thus exacerbating ER stress response and ER $\mathrm{Ca}^{2+}$ leak [14]. Tunicamycin also activates gangliosides biosynthesis [45], thereby interfering with APP processing [46]. A recent study also reported that in vivo tunicamycin administration induced spatial memory deficits and impairments of synaptic plasticity in rats [47]. These data are in agreement with our observations linking S1T in particular and ER stress response in general to AD development and/or progression. Overall, our study provides evidence that S1T expression may impact disease development through the upregulation of $\beta$-secretase-mediated $\beta$ APP processing and neuroinflammatory response using both cellular and in vivo study models. Thus, we propose an amplifying mechanism in a positive feedback loop 
between S1T and amyloidogenic $\beta$ APP processing likely accounting for the enhanced ER stress and neuroinflammation occurring in $\mathrm{AD}$ (Figure 6).

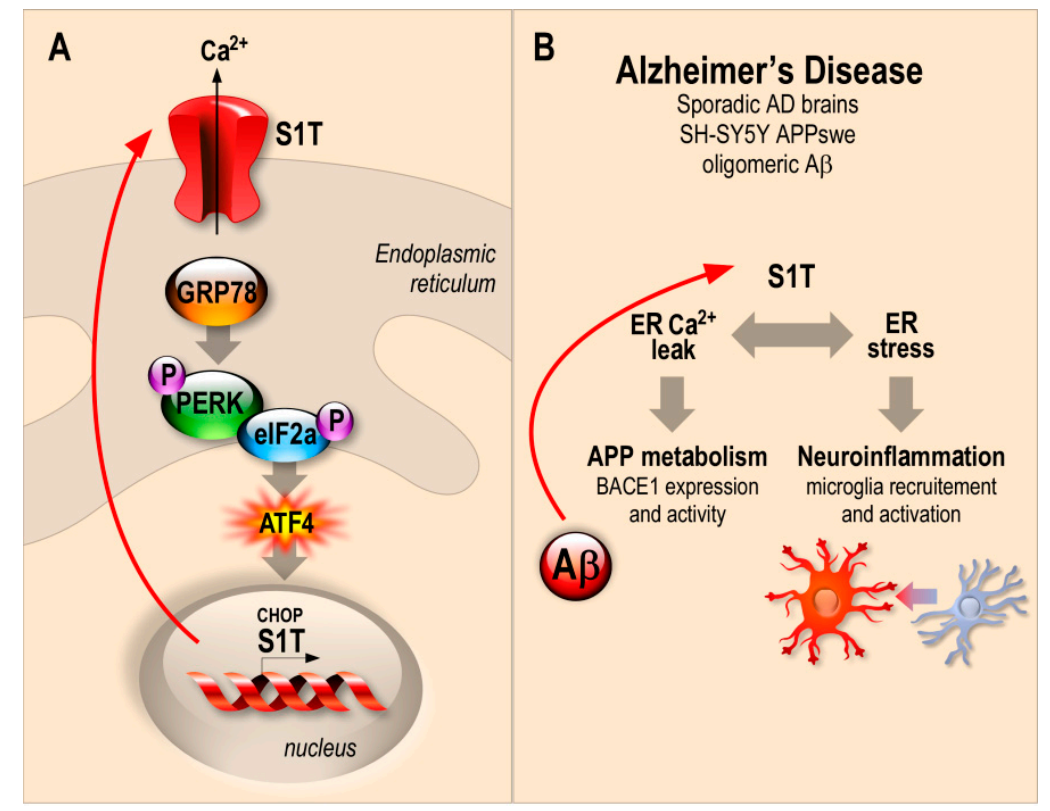

Figure 6. Schematic representation of the molecular interplay between S1T-dependent ER $\mathrm{Ca}^{2+}$ leak, ER stress, $\beta$ APP processing, and neuroinflammation likely contributing to AD setting and/or progression. (A) The human truncated isoform of the sarco-endoplasmic reticulum $\mathrm{Ca}^{2+}$ ATPase 1 (S1T) expression is induced under ER stress conditions through the PERK-eIF2 $\alpha$-ATF4-CHOP pathway, and triggers and amplifies ER stress response through the control of $\mathrm{Ca}^{2+}$ mobilization from ER. (B) S1T is upregulated in sporadic AD brains and in cellular models overproducing $\beta$ APP fragments (SH-SY5Y APPswe). S1T expression is also induced by exogenous oligomeric $A \beta$ and enhances in turn $\beta$ APP processing through enhanced BACE1 expression and activity and triggers microglia recruitment and activation in vitro and in vivo.

Supplementary Materials: The following are available online at http://www.mdpi.com/2073-4409/8/12/1539/s1.

Author Contributions: M.C. conceived and designed the study, conducted studies, analyzed data, wrote and edited the manuscript. B.O. and M.C. conducted studies and analyzed data of human AD cohort. R.B. conducted studies and analyzed data in cellular models, the 3xTg-AD and tunicamycin treated mice. C.M. conducted studies and analyzed data in cellular models. D.V. conducted BACE1 expression and activity, W.E.M., E.D., and C.A.D.C. conceived tunicamycin mice model, and obtained brain protein and mRNA samples. A.M. and L.V.-B. analyzed ER stress and neuroinflammation in tunicamycin treated mice. F.C. analyzed and discussed data and edited the manuscript. All authors read and approved the final manuscript.

Funding: This work was supported by Fondation Vaincre Alzheimer (\#13737) (MC), «Fondation pour la Recherche Médicale» (DEQ20071210550) (PPB, and MC), LABEX (excellence laboratory, program investment for the future) DISTALZ (Development of Innovative Strategies for a Transdisciplinary approach to Alzheimer's disease) (FC), the University Hospital Federation (FHU) OncoAge (FC).

Acknowledgments: We acknowledge the Viral Vector and Gene Transfer Platform, Université Paris Descartes-Sorbonne Paris Cité, Institut Fédératif de Recherche Necker Enfants Malades, 75014 Paris, France for the first lentiviruses productions and "Brainbank Neuro-CEB Neuropathology Network"* as the source of the Biological Material (human brains) and Associated Data. *The NeuroCEB Neuropathology network includes: Franck Letournel (CHU Angers), Marie-Laure Martin-Négrier (CHU Bordeaux), Françoise Chapon (CHU Caen), Catherine Godfraind (CHU Clermont-Ferrand), Claude-Alain Maurage (CHU Lille), Vincent Deramecourt (CHU Lille), David Meyronnet (CHU Lyon), Nathalie Streichenberger (CHU Lyon), André Maues de Paula (CHU Marseille), Valérie Rigau (CHU Montpellier), Fanny Vandenbos-Burel (Nice), Charles Duyckaerts (CHU PS Paris), Danielle Seilhean (CHU PS, Paris), Susana Boluda (CHU PS, Paris), Isabelle Plu (CHU PS, Paris), Serge Milin (CHU Poitiers), Dan Christian Chiforeanu (CHU Rennes), Annie Laquerrière (CHU Rouen), Béatrice Lannes (CHU Strasbourg).

Conflicts of Interest: The authors declare that they have no conflicts of interest. 


\section{References}

1. Scheltens, P.; Blennow, K.; Breteler, M.M.; De Strooper, B.; Frisoni, G.B.; Salloway, S. Van der Flier WM: Alzheimer's disease. Lancet 2016, 388, 505-517. [CrossRef]

2. Zhang, Y.W.; Thompson, R.; Zhang, H.; Xu, H. APP processing in Alzheimer's disease. Mol. Brain $2011,4,3$. [CrossRef]

3. Del Prete, D.; Checler, F.; Chami, M. Ryanodine receptors: Physiological function and deregulation in Alzheimer disease. Mol. Neurodegener. 2014, 9, 21. [CrossRef]

4. Cadonic, C.; Sabbir, M.G.; Albensi, B.C. Mechanisms of Mitochondrial Dysfunction in Alzheimer's Disease. Mol. Neurobiol. 2016, 53, 6078-6090. [CrossRef]

5. Huang, H.C.; Tang, D.; Lu, S.Y.; Jiang, Z.F. Endoplasmic reticulum stress as a novel neuronal mediator in Alzheimer's disease. Neurol. Res. 2015, 37, 366-374. [CrossRef]

6. Briggs, D.I.; Defensor, E.; Memar Ardestani, P.; Yi, B.; Halpain, M.; Seabrook, G.; Shamloo, M. Role of Endoplasmic Reticulum Stress in Learning and Memory Impairment and Alzheimer's Disease-Like Neuropathology in the PS19 and APP(Swe) Mouse Models of Tauopathy and Amyloidosis. Eneuro 2017. [CrossRef] [PubMed]

7. Scheper, W.; Hoozemans, J.J. The unfolded protein response in neurodegenerative diseases: A neuropathological perspective. Acta Neuropathol. 2015, 130, 315-331. [CrossRef] [PubMed]

8. Zhao, L.; Ackerman, S.L. Endoplasmic reticulum stress in health and disease. Curr. Opin. Cell Biol. 2006, 18, 444-452. [CrossRef] [PubMed]

9. Hetz, C.; Papa, F.R. The Unfolded Protein Response and Cell Fate Control. Mol. Cell 2018, 69, $169-181$. [CrossRef]

10. Hajnoczky, G.; Csordas, G.; Madesh, M.; Pacher, P. The machinery of local $\mathrm{Ca}^{2+}$ signalling between sarco-endoplasmic reticulum and mitochondria. J. Physiol. 2000, 529, 69-81. [CrossRef]

11. Rizzuto, R.; Pinton, P.; Carrington, W.; Fay, F.S.; Fogarty, K.E.; Lifshitz, L.M.; Tuft, R.A.; Pozzan, T. Close contacts with the endoplasmic reticulum as determinants of mitochondrial $\mathrm{Ca}^{2+}$ responses. Science 1998, 280, 1763-1766. [CrossRef] [PubMed]

12. Brough, D.; Schell, M.J.; Irvine, R.F. Agonist-induced regulation of mitochondrial and endoplasmic reticulum motility. Biochem. J. 2005, 392, 291-297. [CrossRef] [PubMed]

13. Chami, M.; Gozuacik, D.; Lagorce, D.; Brini, M.; Falson, P.; Peaucellier, G.; Pinton, P.; Lecoeur, H.; Gougeon, M.L.; le Maire, M.; et al. SERCA1 truncated proteins unable to pump calcium reduce the endoplasmic reticulum calcium concentration and induce apoptosis. J. Cell Biol. 2001, 153, 1301-1314. [CrossRef] [PubMed]

14. Chami, M.; Oules, B.; Szabadkai, G.; Tacine, R.; Rizzuto, R.; Paterlini-Brechot, P. Role of SERCA1 truncated isoform in the proapoptotic calcium transfer from ER to mitochondria during ER stress. Mol. Cell 2008, 32, 641-651. [CrossRef]

15. Blasi, E.; Barluzzi, R.; Bocchini, V.; Mazzolla, R.; Bistoni, F. Immortalization of murine microglial cells by a v-raf/v-myc carrying retrovirus. J. Neuroimmunol. 1990, 27, 229-237. [CrossRef]

16. Oules, B.; Del Prete, D.; Greco, B.; Zhang, X.; Lauritzen, I.; Sevalle, J.; Moreno, S.; Paterlini-Brechot, P.; Trebak, M.; Checler, F.; et al. Ryanodine receptor blockade reduces amyloid-beta load and memory impairments in Tg2576 mouse model of Alzheimer disease. J. Neurosci. 2012, 32, 11820-11834. [CrossRef]

17. Bussiere, R.; Lacampagne, A.; Reiken, S.; Liu, X.; Scheuerman, V.; Zalk, R.; Martin, C.; Checler, F.; Marks, A.R.; Chami, M. Amyloid beta production is regulated by beta2-adrenergic signaling-mediated post-translational modifications of the ryanodine receptor. J. Biol. Chem. 2017, 292, 10153-10168. [CrossRef]

18. De Felice, F.G.; Wu, D.; Lambert, M.P.; Fernandez, S.J.; Velasco, P.T.; Lacor, P.N.; Bigio, E.H.; Jerecic, J.; Acton, P.J.; Shughrue, P.J.; et al. Alzheimer's disease-type neuronal tau hyperphosphorylation induced by A beta oligomers. Neurobiol. Aging 2008, 29, 1334-1347. [CrossRef]

19. Oddo, S.; Caccamo, A.; Shepherd, J.D.; Murphy, M.P.; Golde, T.E.; Kayed, R.; Metherate, R.; Mattson, M.P.; Akbari, Y.; LaFerla, F.M. Triple-transgenic model of Alzheimer's disease with plaques and tangles: Intracellular Abeta and synaptic dysfunction. Neuron 2003, 39, 409-421. [CrossRef] 
20. Andrau, D.; Dumanchin-Njock, C.; Ayral, E.; Vizzavona, J.; Farzan, M.; Boisbrun, M.; Fulcrand, P.; Hernandez, J.F.; Martinez, J.; Lefranc-Jullien, S.; et al. BACE1- and BACE2-expressing human cells: Characterization of beta-amyloid precursor protein-derived catabolites, design of a novel fluorimetric assay, and identification of new in vitro inhibitors. J. Biol. Chem. 2003, 278, 25859-25866. [CrossRef]

21. Umeda, T.; Tomiyama, T.; Sakama, N.; Tanaka, S.; Lambert, M.P.; Klein, W.L.; Mori, H. Intraneuronal amyloid beta oligomers cause cell death via endoplasmic reticulum stress, endosomal/lysosomal leakage, and mitochondrial dysfunction in vivo. J. Neurosci. Res. 2011, 89, 1031-1042. [CrossRef] [PubMed]

22. Del Prete, D.; Suski, J.M.; Oules, B.; Debayle, D.; Gay, A.S.; Lacas-Gervais, S.; Bussiere, R.; Bauer, C.; Pinton, P.; Paterlini-Brechot, P.; et al. Localization and Processing of the Amyloid-beta Protein Precursor in Mitochondria-Associated Membranes. J. Alzheimers Dis. 2017, 55, 1549-1570. [CrossRef] [PubMed]

23. Gerakis, Y.; Dunys, J.; Bauer, C.; Checler, F. Abeta42 oligomers modulate beta-secretase through an XBP-1s-dependent pathway involving HRD1. Sci. Rep. 2016, 6, 37436. [CrossRef]

24. Barbero-Camps, E.; Fernandez, A.; Baulies, A.; Martinez, L.; Fernandez-Checa, J.C.; Colell, A. Endoplasmic reticulum stress mediates amyloid beta neurotoxicity via mitochondrial cholesterol trafficking. Am. J. Pathol. 2014, 184, 2066-2081. [CrossRef] [PubMed]

25. Checler, F. Processing of the beta-amyloid precursor protein and its regulation in Alzheimer's disease. J. Neurochem. 1995, 65, 1431-1444. [CrossRef] [PubMed]

26. Kaether, C.; Haass, C.; Steiner, H. Assembly, trafficking and function of gamma-secretase. Neurodegener. Dis. 2006, 3, 275-283. [CrossRef] [PubMed]

27. Flammang, B.; Pardossi-Piquard, R.; Sevalle, J.; Debayle, D.; Dabert-Gay, A.S.; Thevenet, A.; Lauritzen, I.; Checler, F. Evidence that the amyloid-beta protein precursor intracellular domain, AICD, derives from beta-secretase-generated C-terminal fragment. J. Alzheimers Dis 2012, 30, 145-153. [CrossRef]

28. Salminen, A.; Kauppinen, A.; Suuronen, T.; Kaarniranta, K.; Ojala, J. ER stress in Alzheimer's disease: A novel neuronal trigger for inflammation and Alzheimer's pathology. J. Neuroinflamm. 2009, 6, 41. [CrossRef]

29. Hoozemans, J.J.; Veerhuis, R.; Van Haastert, E.S.; Rozemuller, J.M.; Baas, F.; Eikelenboom, P.; Scheper, W. The unfolded protein response is activated in Alzheimer's disease. Acta Neuropathol. 2005, 110, 165-172. [CrossRef]

30. Hoozemans, J.J.; van Haastert, E.S.; Nijholt, D.A.; Rozemuller, A.J.; Eikelenboom, P.; Scheper, W. The unfolded protein response is activated in pretangle neurons in Alzheimer's disease hippocampus. Am. J. Pathol. 2009, 174, 1241-1251. [CrossRef]

31. Nishitsuji, K.; Tomiyama, T.; Ishibashi, K.; Ito, K.; Teraoka, R.; Lambert, M.P.; Klein, W.L.; Mori, H. The E693Delta mutation in amyloid precursor protein increases intracellular accumulation of amyloid beta oligomers and causes endoplasmic reticulum stress-induced apoptosis in cultured cells. Am. J. Pathol. 2009, 174, 957-969. [CrossRef] [PubMed]

32. Kim, H.S.; Choi, Y.; Shin, K.Y.; Joo, Y.; Lee, Y.K.; Jung, S.Y.; Suh, Y.H.; Kim, J.H. Swedish amyloid precursor protein mutation increases phosphorylation of eIF2alpha in vitro and in vivo. J. Neurosci. Res. 2007, 85, 1528-1537. [CrossRef] [PubMed]

33. Rutkowski, D.T.; Arnold, S.M.; Miller, C.N.; Wu, J.; Li, J.; Gunnison, K.M.; Mori, K.; Sadighi Akha, A.A.; Raden, D.; Kaufman, R.J. Adaptation to ER stress is mediated by differential stabilities of pro-survival and pro-apoptotic mRNAs and proteins. PLoS Biol. 2006, 4, e374. [CrossRef] [PubMed]

34. Stutzbach, L.D.; Xie, S.X.; Naj, A.C.; Albin, R.; Gilman, S.; Group, P.S.P.G.S.; Lee, V.M.; Trojanowski, J.Q.; Devlin, B.; Schellenberg, G.D. The unfolded protein response is activated in disease-affected brain regions in progressive supranuclear palsy and Alzheimer's disease. Acta Neuropathol. Commun. 2013, 1, 31. [CrossRef]

35. Unterberger, U.; Hoftberger, R.; Gelpi, E.; Flicker, H.; Budka, H.; Voigtlander, T. Endoplasmic reticulum stress features are prominent in Alzheimer disease but not in prion diseases in vivo. J. Neuropathol. Exp. Neurol. 2006, 65, 348-357. [CrossRef]

36. Hashimoto, S.; Ishii, A.; Kamano, N.; Watamura, N.; Saito, T.; Ohshima, T.; Yokosuka, M.; Saido, T.C. Endoplasmic reticulum stress responses in mouse models of Alzheimer's disease: Overexpression paradigm versus knockin paradigm. J. Biol. Chem. 2018, 293, 3118-3125. [CrossRef]

37. Hashimoto, S.; Saido, T.C. Critical review: Involvement of endoplasmic reticulum stress in the aetiology of Alzheimer's disease. Open Biol. 2018, 8, 180024. [CrossRef] 
38. Sadleir, K.R.; Popovic, J.; Vassar, R. ER stress is not elevated in the 5XFAD mouse model of Alzheimer's disease. J. Biol. Chem. 2018, 293, 18434-18443. [CrossRef]

39. Pera, M.; Larrea, D.; Guardia-Laguarta, C.; Montesinos, J.; Velasco, K.R.; Agrawal, R.R.; Xu, Y.; Chan, R.B.; Di Paolo, G.; Mehler, M.F.; et al. Increased localization of APP-C99 in mitochondria-associated ER membranes causes mitochondrial dysfunction in Alzheimer disease. EMBO J. 2017, 36, 3356-3371. [CrossRef]

40. Chang, R.C.; Suen, K.C.; Ma, C.H.; Elyaman, W.; Ng, H.K.; Hugon, J. Involvement of double-stranded RNA-dependent protein kinase and phosphorylation of eukaryotic initiation factor-2alpha in neuronal degeneration. J. Neurochem. 2002, 83, 1215-1225. [CrossRef]

41. Page, G.; Rioux Bilan, A.; Ingrand, S.; Lafay-Chebassier, C.; Pain, S.; Perault Pochat, M.C.; Bouras, C.; Bayer, T.; Hugon, J. Activated double-stranded RNA-dependent protein kinase and neuronal death in models of Alzheimer's disease. Neuroscience 2006, 139, 1343-1354. [CrossRef] [PubMed]

42. O'Connor, T.; Sadleir, K.R.; Maus, E.; Velliquette, R.A.; Zhao, J.; Cole, S.L.; Eimer, W.A.; Hitt, B.; Bembinster, L.A.; Lammich, S.; et al. Phosphorylation of the translation initiation factor eIF2alpha increases BACE1 levels and promotes amyloidogenesis. Neuron 2008, 60, 988-1009. [CrossRef] [PubMed]

43. Devi, L.; Ohno, M. PERK mediates eIF2alpha phosphorylation responsible for BACE1 elevation, CREB dysfunction and neurodegeneration in a mouse model of Alzheimer's disease. Neurobiol. Aging 2014, 35, 2272-2281. [CrossRef]

44. Chami, L.; Checler, F. BACE1 is at the crossroad of a toxic vicious cycle involving cellular stress and beta-amyloid production in Alzheimer's disease. Mol. Neurodegener. 2012, 7, 52. [CrossRef] [PubMed]

45. Guarnaccia, S.P.; Shaper, J.H.; Schnaar, R.L. Tunicamycin inhibits ganglioside biosynthesis in neuronal cells. Proc. Natl. Acad. Sci. USA 1983, 80, 1551-1555. [CrossRef] [PubMed]

46. Grimm, M.O.; Zinser, E.G.; Grosgen, S.; Hundsdorfer, B.; Rothhaar, T.L.; Burg, V.K.; Kaestner, L.; Bayer, T.A.; Lipp, P.; Muller, U.; et al. Amyloid precursor protein (APP) mediated regulation of ganglioside homeostasis linking Alzheimer's disease pathology with ganglioside metabolism. PLoS ONE 2012, 7, e34095. [CrossRef] [PubMed]

47. Lin, L.; Cao, J.; Yang, S.S.; Fu, Z.Q.; Zeng, P.; Chu, J.; Ning, L.N.; Zhang, T.; Shi, Y.; Tian, Q.; et al. Endoplasmic reticulum stress induces spatial memory deficits by activating GSK-3. J. Cell Mol. Med. 2018, 22, 3489-3502. [CrossRef] 